\title{
The Role of Big Data Quality and Information Analytics in Indonesia Higher Education Sector during Covid-19 Pandemic
}

\author{
Faisal Syafar, Halimah Husain, Edy Sabara
}

\begin{abstract}
The COVID-19 pandemic has changed our habits, both in work, worship, and study. Since beginning, the health and safety of students, lecturers and employees are the Ministry of Education and Culture of Indonesia's main concern. In the environment of higher education (HE) it turns out that in a short time there is a transformation in the use of technology for learning online. Apart from the various obstacles faced by lecturers and students, it turns out that the adaptability of lecturers and student very fast. Online learning is encouraging independent learning ability, as an essential competency in this $21^{\text {st }}$ century. Creativity and productivity of lecturers and students also did not decrease. Thousands of technology innovation related to education and health is produced and created by universities. Seeds creativity and innovation in higher education precisely sprout in this global pandemic. This paper presents the current role and advantages of big data and information analytic in Indonesia $\mathrm{HE}$ institutions.
\end{abstract}

Index Terms - big data, information quality, higher education, pandemic COVID-19

\section{INTRODUCTION}

Big Data is creating significant new opportunities for organizations to derive new value and create competitive advantage from their most valuable asset: information. For higher education (HE) institutions, big data helps drive efficiency, quality, and personalized learning and services, producing improved levels of alumni satisfaction. For scientific efforts, big data analytics enable new avenues of investigation with potentially richer results and deeper insights than previously available. In many cases, big data analytics integrate structured and unstructured data with realtime feeds and queries, opening new paths to innovation and insight [1].

In HE, big data is not about moving the bottom line or improving valuations, and it's not that they don't have data - they're collecting hundreds of thousands of data points per day from online assessments, learning management systems, open online courses, and more.

Faisal Syafar, Department of Electronics, Universitas Negeri Makassar, Makassar, Indonesia

Halimah Husain, Department of Chemistry, Universitas Negeri Makassar, Makassar, Indonesia

Edy Sabara, Department of Electronics, Universitas Negeri Makassar, Makassar, Indonesia
The main goal of big data and information analytics in HE institutions is to improve teaching and learning process. There is a real power behind big data's ability, particularly in the area of personalized learning. In brief, data analytics empowers university lecturers and professors of large courses to get a clear understanding of their students' existing capabilities, skill sets, and learning gaps, both on an individual level and as group, and then tailor the curriculum to meet each class's unique needs. During the Covid-19 pandemic, and beyond, mixing those big data analytics with all driven learning platforms, professors can offer supplemental materials designed to ensure that each and every student gets the support and value from the course.

In Indonesia $\mathrm{HE}$ institutions context, several initiation programs by the Ministry of National Education and Culture (MNEC) has colored the practice of implementing distance learning in Indonesia, are as follows.

1. Hylite (Hybrid Learning for Indonesian Teachers), which is a primary school teacher qualification improvement program.

2. Diploma level D3 Program in Computer and Network Engineering (TKJ) involving 69 universities in 2006.

3. PDITT (Open Indonesian Online Learning and Integrated) which was initiated in 2013 to serve "blank served", taking advantage of the advantages of the university generally in Java, by giving quality learning services for students at throughout Indonesia. PDITT involves 6 (six) universities, namely: Bandung Institute of Technology, Institute of Technology Sepuluh November Surabaya, STMIK AMIKOM Yogyakarta, Bina Nusantara University, Gadjah Mada University, and University of Indonesia.

4. SPADA (Online Learning System) which is programs to encourage development and dissemination of open learning materials (open educational resources or OER), administration open online lectures massive open online model courses (MOOCs), and regular online courses. To date, SPADA involves no less than 54 Universities.

Quality big data and information analytic has the potential in offering significant benefit over online learning with various online learning platform (synchronous and asynchronous). This research therefore aimed to investigate how can HE institutions in Indonesia benefit from the use of big data analytic during Covid-19 pandemic. 


\section{THEORETICAL FOUNDATION}

Big data analytics is the use of advanced analytic techniques against very large, diverse data sets that include structured, semi-structured and unstructured data, from different sources, and in different sizes from terabytes to zettabytes.

Big data is a term applied to data sets whose size or type is beyond the ability of traditional relational databases to capture, manage and process the data with low latency. Big data has one or more of the following characteristics: high volume, high velocity or high variety. Artificial intelligence (AI), mobile, social and the Internet of Things (IoT) are driving data complexity through new forms and sources of data. For example, big data comes from sensors, devices, video/audio, networks, log files, transactional applications, web, and social media - much of it generated in real time and at a very large scale [2].

Analysis of big data allows analysts, researchers and business users to make better and faster decisions using data that was previously inaccessible or unusable. Higher education institutions can use advanced analytics techniques such as text analytics, machine learning, predictive analytics, data mining, statistics and natural language processing to gain new insights from previously untapped data sources independently or together with existing enterprise data.

Over the last five years or so, big data analytics and automated processes have become increasingly prevalent in HE. Many functions, practices and tasks of HE is being made 'machine-readable' by digital technologies, as teaching, learning and administration are transformed by 'datafication' [3]. Datafication is also advancing automation, as the processing of digital information by increasingly capable or 'smart' technologies makes it possible to automate many tasks. As universities have now begun to consider a future disrupted by Covid-19 that seems likely to be characterized by distance learning, datafication and automation may expand and intensify across the sector.

Online program management (OPM) refers to infrastructure services provided by vendors to enable universities to deliver online and distance education courses. Currently growing rapidly in Indonesia, OPM service providers also provide extensive data analytics in their platforms, offering convenient ways to automate student tracking and monitoring. OPM companies include 2U, Noodle Partners and Academic Partnerships, big education publishers, including Wiley and Pearson, as well as MOOC providers that have diversified into the OPM market [4].

\section{Pandemic markets}

The rush to remote education and online degrees is now a significant market event. OPMs, claims the education market intelligence consultancy HolonIQ, constitute part of a \$7billion 'Global OPM and Academic Public Private Partnership Market' that 'COVID-19 will substantially accelerate' to a $\$ 15$ b market by 2025 :

\begin{abstract}
More so today (COVID-19) than ever, Universities around the world are increasingly seeking private partners to rapidly build capability, to boost and differentiate their offerings, accelerate growth and achieve long-term sustainability. As such, Private Equity and Capital Markets are watching the Academic PPP segment closely.
\end{abstract}

Moreover, OPMs are a key growth technology in a much larger Global Online Higher Education market valued by HolonIQ at \$36billion in 2019 and projected to rise to \$74b by 2025, opening up new 'opportunities' for market providers:

These changes to market dynamics are likely to accelerate with COVID-19, and while the biggest online players are gaining market share on the strength of their national reach and brands, this is the opportunity for predominantly offline providers to amplify their current online offerings with existing and new learners.

\section{Research Questions}

1. What is online learning mode and characteristic of data and information should HE Institutions looking for?

2. What HE Institutions should prepare to support sharing online learning?

3. How can Higher Education Institutions in Indonesia benefit from Covid-19 Pandemic Big Data of online learning?

\section{RESEARCH METHOD}

National survey. Purpose of the national survey is for:

1) answer research questions,

2) provides an overview of the online learning mode, Universities preparation related quality big data and information which is later will be verified by the findings obtained in next stage of research (year 2021). At this stage at least 500 respondents received a questionnaire link (online) and or via electronic mail attachment (Email) with the target role/position respondents are elements of the leadership of HE (Chancellor, Assistant/Deputy Chancellor; Dean, Assistant/Deputy Dean, Head of Study Program, Director/Head of ICT Center, Director/Head of Quality Assurance Center), Data Collectors, Operators, and Technicians.

The population of this survey is both public and private HE institutions (Universities, Institutes, Colleges, Academies) scattered on all major islands in Indonesia (Sumatra, Java, Bali, Kalimantan, Sulawesi, Maluku and Papua).

National Survey Data Analysis: The SPSS program was used for survey data analysis includes ANOVA (individual variable for each category of University); MANOVA (used to determine whether there is distinction between group of targeted respondent perspectives related to the beneficial of big data analytic implementation in HE institutions). 


\section{RESEARCH FINDINGS AND DISCUSSIONS}

\section{Online Learning Mode and characteristic of data and information in HE Institutions}

Online learning mode, performed by the end of September, $100 \%$ of HE Institutions had done learning from home. Of these $98.2 \%$ doing online learning, less than $2 \%$ did other forms of learning. Most of the students (68.7\%) use mobile phones for learning online, $14.3 \%$ use notebooks, $10.7 \%$ desktops, $0.7 \%$ tablets, and $5.6 \%$ other equipment. This shows that the cellphone has become a major online learning device used. Even ones using equipment other than a cellphone also has a lot of connections that is done through tethering to the cellphone, this is visible $76.6 \%$ of the internet connection data use the connection via cellphone or tethering, while WIFI $22.2 \%$, and LAN only $0.3 \%$.

Online lectures can be held synchronously or asynchronous. Many lecture methods used in the first month of learning online is a mixture of synchronous and asynchronous $(39.5 \%)$, while only $34.7 \%$ using asynchronous mode, while the full synchronous $20,1 \%$. Learning platform that are widely used for synchronous learning are zoom (33.2\%) and google meet $(33.8 \%)$, while quite a lot are also universities who already has its own online lecture platform (LMS, SPADA) with a comprehensive system.

\section{HE Institutions preparation to support sharing online learning}

To facilitate online lecture activities, the Directorate General Higher Education of MNEC of Indonesia made several initiations in order to facilitate distance learning, including:

1) provision of online learning platforms and resources learning at https://spada.kemdikbud.go.id;

2) provision of online resources and online platform can be accessed free of charge, in cooperation with Google;

3 ) access to SPADA platforms and learning pages as well URLs to learning websites at colleges included in the toll-free white-list;

4) providing low-cost internet access for lecturers and students cooperate with telecommunication providers;

5) providing training and capacity building for lecturers / academicians in material development online learning;

6) providing opportunities to organize inter-university online learning credit recognition program; and

7) granting permission to use MOOCs from the provider international.

Now after one semester online lectures are running on during the Covid-19 pandemic, we saw a lot of learning can be picked. The case of the spread of Covid-19 in Indonesia still not showing a significant decrease. Data on September 10, 2020, it still shows its height new cases in several provinces in Indonesia, with the number of new cases was 3861 , which is much higher of the number of patients who recovered, which was only 2310 people. Thus, it seems that the situation is not quite yet under control and many regions still apply status Large-Scale Social Restrictions (PSBB). Hence, process learning in $\mathrm{HE}$ in the semester to be it still seems that it is still not fully coming back 'Normal' as before. Distance learning and especially learning online seems to still be coloring if it is not dominate the lecture process at various universities nationwide. This matter also indicated by the results of various surveys conducted, both in Indonesia and abroad. Experience one semester this should be a learning valuable so that the next online learning process can be organized in a more planned, structured, systematic, and quality.

The Corona virus that came suddenly was able to revolutionize perspective, mindset, and behavior patterns of the academic community of Indonesian HE. Uncertainty has turned into opportunities to innovate. The Directorate General of Higher Education of Indonesia are also negotiates with internet providers service with the Ministry of Communication and Information to obtain ease the burden of online learning costs. Supporting that has been carried out by internet service providers including:

1) enter the URL of the learning page (SPADA, home learning, online learning platform from the campus) to the unpaid white-list.

2) provides pocket-friendly data packages students, either in the form of a discount or package application bundle.

3 ) provides a synchronous learning platform at low costs, such as CloudX and Umeetme.

\section{Data about student engagement and learning}

Most of targeted respondents argue that we need to know which students have access to online learning and which students are present, the questions they have about the content they are learning, capture their work product and try to code it and categorize it in ways that let us know what is actually happening in teaching and learning. Other respondents said, we need to know what resources teachers need and which teachers need technical or adaptive support so that they can do what is basically a new job in new ways. And then we need to think about what those things mean in terms of creating systems that capture those answers coherently, not just as a result of the crisis but as a way to develop coherent instructional systems.

The data that was being used to drive decisions before the coronavirus (e.g. attendance, classroom grades, diagnostic and formative assessments) is likely still the right information and it just becomes more pronounced and important in the absence of standardized test scores. The rapid onset of the pandemic, coupled with the emergence of acute and novel student needs, has really underscored the importance of accessible, integrated, actionable quality big data. It has helped us to counteract the inequitable impact that the pandemic has had on people of color and low-income households. Ensuring equitable access and outcomes is even more urgent and important than even a few months ago. 


\section{Higher Edacation Institutions benefit from Covid-19 Pandemic Big Data of online learning?}

With HE institutions increasingly connecting with their students via the internet, opportunities for the collection and utilisation of big data in university recruitment and pedagogical innovation are growing. The Guardian held an online forum in July which discussed the need for big data in $\mathrm{HE}$ and what limits, if any, should be placed on its collection. It revealed some contrasting points of view from $\mathrm{HE}$ professionals, with many singing the praises of data collection, as long as it's done with caution.

The belief is still held strongly that big data can help to improve student performance, enhance logged in virtual learning environment (VLE in educational technology), amount of resources accessed and number of submissions will give a representation of the student experience that is still, despite its limitations, very measurable and comparable. When combined with other information such as behavior on social media, notes from professors, blogs and surveys, it's possible to paint a fairly clear picture of student behavior and the overall performance of the university. However, a lot of data is still being tracked for no real reason.

\section{How can universities use big data?}

The big topic for debate comes when deciding how best to use the data that universities collect. Data analysis used for the benefit of students and the improvement of university services is generally considered to be acceptable. The line is generally drawn at marketing products and services that are more about profit than progress. Big data still has the ability to provide prospective students with more information and better options, thus enabling universities to improve both student performance and student recruitment in several key ways:

\section{Student recruitment}

Big data from current and former students such as historical performance and demographics could

be used to create student profiles. HE institutions could then incorporate information of behavior of past and current students on social media in order to more effectively target their ideal candidates for student recruitment.

\section{Improve student performance}

It can usually be agreed that using data to help current students stay on course towards a good Final grade is a good idea. Test results and academic performance can easily be tracked and compared to previous performance as well as those of similar students. Other data such as teacher notes and social media data can give more of an insight to a student's behavior and flag up any significant changes in performance.

\section{Teacher effectiveness}

Sometimes students fall behind due to stress, family issues or other factors that are beyond our control; one factor that we can control, or at least monitor is the effectiveness of our teaching staff. This is not necessarily a method of holding the teaching staff accountable for how the students perform, but as a metric to help them be their most effective. Which courses do they teach that have the highest engagement from students? What methods and tools do they use (such as VLEs and online lectures) and how effective are they?

\section{Learning Effectiveness}

When students are asked about understanding of the learning material online, $70 \%$ said moderate to very well. This is quite encouraging, considering the preparations relatively short online learning. Even response students to the question how good the lecturer is delivered lecture material online, $85 \%$ of respondents Moderate to very good. Proportion of answers the same was obtained when students were asked about the quality of the presentation of online course material.

\section{Online Learning Constraints}

As might be expected, the main obstacle to online learning is the lack of readiness of internet facilities to support online learning. As acknowledged, most of the students have returned to their villages and use the phone as a source of internet connection. So that the availability of internet network (coverage) and the quality of internet service still varies widely Indonesia is reflected in the response of students. As of $31 \%$ respondents stated that they were not ready to take part in learning online due to network, $21 \%$ due to network instability, $11 \%$ because the quota is insufficient, $8 \%$ of students are stated that the facilities owned are truly ready (speed and adequate quotas).

\section{Pros and Cons of Online Learning}

Various advantages of online learning are felt by college student. Most of the respondents said online learning is a new experience (26\%). Twenty-four percent of students said they had advantages online is because there is no need to go to campus. Flexibility and it is a relaxing atmosphere through learning from home advantages stated by $20.4 \%$ of respondents. Strengths among others: more documented material $(9.7 \%)$, more time efficient $(9.5 \%)$, and bolder asked (7\%). Meanwhile the drawbacks of online learning are the most complained by the students was the network's unpreparedness internet (41\%), excessive workload (26.8\%), lectures replaced by tasks $(9.8 \%)$, the concentration sometimes decreased $(9 \%)$, lecturers are less interactive $(4.3 \%)$, and schedule changes (1.6\%).

\section{CONCLUSION}

It is hoped that both lecturers and higher education institutions are revolutionizing the learning model classic known so far. Learning models and concepts modern such as blended learning, flipped classroom, online collaboration learning, edutainment, gamification, seamless learning, project-based learning, smart learning, and others must be present in various learning designs prepared by the learning system architects. It is in this situation that digital literacy will find its momentum is the main requirement for those who wish to enter and succeed in a HE environment at wherever the person concerned. Big data still has the ability to provide prospective students with more information and better options, thus enabling universities to improve both student performance and student recruitment in several key ways. 


\section{REFERENCES}

[1] EMC Education Services, 2015,'Data Science \& Big Data Analytis', John Wiley \& Sons, Inc., USA.

[2] IBM, 2020' Big Data Analytic' https://www.ibm.com/analytics/hadoop/big-data-analytics.

[3] Ben Williamson (2020), 'Datafication and automation in higher education during and after the Covid-19 crisis', on May 6, 2020.

[4] MoocLab, 2020,'COVID 19: Coursera, edX \& FutureLearn Offering Free Online Courses to Millions of Students 